\title{
Trabalho, desenvolvimento e nacionalismo: Desafios atuais da periferia estrutural do sistema
}

\begin{abstract}
Maria Orlanda Pinassi*
A história da filosofia, da mesma forma que a da arte e da literatura, não é [...] simplesmente a história das idéias filosóficas ou das personalidades que a sustentam. É o desenvolvimento das forças produtivas, o desenvolvimento social, o desenvolvimento da luta de classes que coloca os problemas à filosofia e indica a esta os roteiros para a sua solução.
\end{abstract}

G. Lukács. El asalto a la razón.

Wo final dos anos de 1990 realizamos uma pesquisa sobre 0 apreender a função social das ideologias ali difundidas e seu reflexo sobre a formação da nacionalidade brasileira, já que alguns dos nossos mais importantes "homens do império" associaram-se à agremiação. Considerando a dependência genética que uma instituição dessa natureza guarda em relação ao que Lukács diz sobre "as forças motrizes de ordem primária", nosso ponto de partida foi compor o sentido que adquire na cena sócio-histórica do imediato pós-revolução, período que impôs uma completa transfiguração das ideologias burguesas clássicas do século XVIII em ideologias apologéticas.

Partimos da premissa de que os condicionamentos ontológicos entre o mundo das idéias e o mundo da produção material

Professora livre-docente do Departamento de Sociologia, Faculdade de Ciências e Letras, UNESP, campus de Araraquara. Autora dos livros Três Devotos, uma Fé, Nenhum Milagre (Editora UNESP, 1998) e Da Miséria Ideológica à Crise Estrutural do Capital: uma Reconciliação Histórica (Boitempo Editorial, no prelo). Membro do comitê de redação da revista Margem Esquerda. Endereço eletrônico:mpinassi@fclar.unesp.br.

1 Essa pesquisa foi realizada junto ao Centro de Estudos Brasileiros, IFCH/UNICAMP, com auxílio financeiro da FAPESP (1997/1999). 
correspondente são, a rigor, substantivos ao conceito de decadência ideológica desenvolvido por Lukács ${ }^{2}$, filósofo que, para as condições do século XX, comprovou ser este um dos mais férteis instrumentos de análise da ciência marxiana da história. E, para ele, o momento predominante ao conceito coincide com a conclusão dos esforços revolucionários da burguesia e o início da sua hegemonização, da sua localização social na estrutura de comando do capital. Com isso apreende-se que o sentido histórico da decadência ideológica é inversamente proporcional - e absolutamente necessário - aos fabulosos desenvolvimentos material e tecno-científico deflagrados a partir daí. Há que se ressaltar ainda que as ideologias, assim entendidas, estabelecem compromisso tão-somente com a reprodução social incessante da ordem, mitigando as resistências e amaciando o curso de controle.

Pensando nisso, consideramos que a imperativa necessidade de expansão/acumulação do capital impõe, ainda no início do século XIX, a ampliação de uma nova e muito mais imbricada divisão social internacional do trabalho. À época, a supressão da relação tipicamente monopólica do estatuto colonial foi a condição exigida dos Estados nacionais em processo de formação que deveriam, então, habilitar-se para o exercício da concorrência, cujas regras vinham reguladas pelo livre comércio mundial.

Estavam ali fundados os marcos iniciais do sistema sóciometabólico do capital bem como de sua longa (e peregrina) fase de ascensão histórica. Por conseguinte, uma também nova concepção das diferenças entre o "velho" e o "novo" mundo começou a interpretá-los como produtos - (ainda) não sintonizados - de

2 “[...] a apologética, considerada metodologicamente, parte da inchação sem reservas de uma generalização justificada dentro de certos limites; e este resultado se obtém 'liberando' o conceito de universalidade de toda relação dialética (determinação, delimitação, enriquecimento, concretização etc.) com a particularidade; a abstrata concepção apologética do universal liquida, pois, ao mesmo tempo a dialética do universal e do particular, ou admite, em suma, uma pseudodialética formal. [...] a dialética do universal e do particular, a ulterior determinação daquele por esta dialética, reflete em forma lógica o fato fundamental da processualidade e historicidade de toda formação econômica, incluído o capitalismo. A dissolução da dialética antes aludida é ao mesmo tempo dissolução do modo de consideração histórico" (LUKÁCS, 1965, p. 102). 
realidades físicas e históricas distintas, mas que, apesar disso, todas estariam destinadas, pelo progresso, a resultados, senão idênticos, ao menos aproximados.

\section{Origens do nacionalismo quimérico}

Lá e cá a euforia brotava da devoção nas teorias que apresentavam o sistema como uma estrutura maleável, moldável e receptiva à correção de todo e qualquer problema interposto à sua reprodução. ${ }^{3}$ De fato, o processo de desenvolvimento desencadeado, desde aí em escala planetária, superou até mesmo as melhores expectativas depositadas sobre a sua capacidade de produzir riqueza, em que pese o fato de ser, ao fim e ao cabo, produto de trabalho social abstrato.

Se o sucesso do intento dependia tão fortemente da superação dos últimos obstáculos que impediam o caminho da modernização capitalista no Brasil da época, o passo mais largo na direção dessa condição ideal fora dado pela Independência e pela chance de finalmente conduzir suas próprias experiências sem a chancela da metrópole. Ademais, a inferiorizada condição de nação marcada pelo domínio colonial poderia ser removida dos seus anais desde que houvesse disposição interna em liberar as potencialidades atrofiadas pelo obscurantismo português.

Essa era a idéia que vigorava entre alguns brasileiros ilustrados; concretamente, porém, o país lançava-se ao mercado com os mesmos produtos agrícolas de origem colonial extraídos do sobretrabalho escravo no eito dos latifúndios desenhados pela monocultura. Assim permaneceria por ainda muito tempo sem que a situação causasse maiores constrangimentos ao oportuno liberalismo. Menos vexados ainda ficavam os escravocratas no

3 Antes disso - "ou da constelação de fatores que com ele se ligam - não se poderia falar a rigor de uma 'história do Brasil'. No país-colônia, sem dúvida, acontecem 'fatos históricos', mas a trama de suas conexões é 'exterior' ao país em que eles se passam. Verificam-se, na terra brasileira, sucessos que só ganham o seu inteiro significado se inseridos na contextura histórica de outras nações, das quais realmente fazem parte. Os episódios da nossa história colonial são, em larga margem, episódios da história portuguesa, espanhola, francesa, holandesa, que se passam foram do território desses países” (SPENCER DE BARROS, 1973, p. XIII). 
Brasil, satisfeitos com a oportunidade de finalmente poderem, eles mesmos, apresentar-se ao grande mercado mundial com suas sacas de café, de açúcar, de fumo, de algodão e afins.

O problema não era exatamente esse. A urgência maior vinha da necessidade de polir o espírito miúdo, de melhorar os hábitos contaminados pela rudeza da colônia, de regozijar-se com as muitas novidades - em grande parte, ainda mais miúdas - que a Europa, sobretudo na França, criava e impunha como condição da sua eletiva aceitação. Não coincidentemente, o IHP, entre muitas outras instituições do gênero fundadas no período, reunia qualidades ao gosto e conveniência da época, razão suficiente para supormos que seus fundamentos refletem o cansaço criativo de uma burguesia necessitada de acomodamentos para poder acumular em paz.

No plano interno da política francesa, por exemplo, o papel do Instituto foi o de render tributo à ordem estabelecida pela monarquia constitucional encabeçada por um pouco democrático rei burguês. Uma contradição nos termos do próprio liberalismo em sua origem clássica, mas os tempos eram muito outros e justamente por isso é que, no plano externo, o IHP ofereceu os fundamentos de um ecletismo que ajudaria a apaziguar os ânimos, particularmente exaltados das nações novas, ainda indefinidas. A julgar por seus resultados no Brasil, conclui-se que foram férteis aquelas lições de civilidade instrumentada e modernização pacífica.

Por essas e por outras, o IHP abre suas portas para o mundo eivado de atraso, de exotismos e "maus modos" com um conceito - muito questionável, por sinal - de cosmopolitismo ${ }^{4}$, já que a real intenção daquela hospitalidade toda foi garantir para a França longa vida à influência ideológica que logrou exercer

4 "Um francês, diz M. Blanc, é necessariamente cosmopolita. Sim, num mundo onde somente reinasse a influência francesa, os modos, os usos e costumes, as idéias e as condições políticas francesas! Num mundo onde cada nação tomaria as qualidades características da nacionalidade francesa! Mas, contra isso, os democratas das outras nações são obrigados a protestar. Totalmente dispostos a abandonar o rigor de sua própria nacionalidade, eles esperam o mesmo dos franceses. Não lhes basta que os franceses thes dêem a garantia de que, na qualidade de franceses, eles já são cosmopolitas. Tal garantia leva à exigência de que todos os outros se tornem franceses" (ENGELS apud LÖWY, 2000, p. 15). 
sobre as nacionalidades de muitos países de extração colonial, entre os quais o Brasil. ${ }^{5}$

Ordem, moderação, espírito eclético, pluralismos moldados por postulados morais e religiosos, institucionalização da sociedade civil sob o controle de um Estado "soberano", suficientemente liberal ou liberal na medida para caber na necessidade de cada nação demandante do progresso capitalista. Eis alguns dos legados do Instituto, celeiro de idéias - de resto, decadentes - que no Brasil tão bem vestiram os ideários nacionalistas do Império, da República...

Pois bem, tudo leva a crer que as relações que se estabelecem no espaço do livre comércio mundial, desde as primeiras décadas do século XIX, sejam o prelúdio da grande vaga imperialista que, no século seguinte, iria recompor, muito mais agressivamente, a tendência monopólica e neocolonial do sistema de reprodução social regido pelo capital. Enfim, os fatos não nos deixam negar que, desde o princípio, a ordem internacional foi obrigada:

A impor - e a constantemente reforçar - a posição altamente privilegiada do punhado de nações preparadas para o imperialismo e, ao mesmo tempo, teve de impor, com todos os meios disponíveis, inclusive os mais violentos "sistematicamente inventados", uma condição de subordinação a todas as nações. (MÉSZÁROS, 2004, p. 22).

\section{A particularidade brasileira e o fracasso do progresso humanizador}

Passado século e meio das primeiras experiências internacionais entre nações "maiores" e nações "menores", assim adjetivadas de acordo com o grau de acumulação de capital observado em cada uma delas, conclui-se que o culto ao progresso e à ciência "útil" jamais pode obter resultados realmente universais, nem, consequientemente, reverter o quadro mais adverso para alguns do que para outros.

5 A França serviu de fonte inspiradora, exemplo de país que se submetera a uma traumática ruptura com o passado em benefício da humanidade com a qual generosamente se dispunha a partilhar os resultados positivos a fim de evitarlhes os "aborrecimentos" advindos de uma revolução social dali em diante considerada desnecessária. 
Pelo contrário, as desigualdades tidas inicialmente como "desvios de percurso", fenômenos passageiros e suprimíveis pelos "mercadores da igualdade", são, na verdade, contradições sociais absolutamente estruturais ao funcionamento hierárquico do sistema.

Os fatos assim posicionados convertem as otimistas previsões universalistas do "liberalismo tolerante" numa das mais poderosas e bem sucedidas místicas do século XIX. ${ }^{6}$ E se vem daí a ideologia regeneradora das iniquiidades históricas - ideologia a serviço da qual o IHP foi vetor, tão mais influente quanto mais medíocre a sua atuação - conclui-se que a instituição tenha contribuído com o caráter quimérico da nossa nacionalidade de província, nacionalidade concebida para ser de periferia.

Consciente ou inconscientemente, no Brasil, a noção de subalternidade acabou gerando um permanente estado de vigília em torno da questão nacional. Apologistas ou críticos, conservadores, reacionários e progressistas, todos saíram em defesa da soberania do país. E, ressalvadas as propostas regressivas que preconizaram a conversão do país ora num imenso latifúndio, ora numa profusão de pequenas propriedades, as demais renderam tributo à fundação dos alicerces necessários ao desenvolvimento do capitalismo industrial no Brasil.

Neste sentido, a questão nacional já nasceu por aqui com caráter reativo/defensivo por meio do qual vem se expressando a esperança de libertar o país do atraso crônico e da renhida dominação estrangeira. E tenha sido ela colonial, pós-colonial, neocolonial, seu significado histórico vem, ao que tudo indica, insistindo em permanecer colonial.

Assim colocada, a questão remete para um debate bastante ativo no Brasil até pouco tempo atrás; debate que, de certa forma, também insere-se na vigília nacional acima aludida. Estamos falando do esforço de expressivos intelectuais brasileiros que, no campo

6 "É claro que a ideologia dominante tem interesse patente na preservação do status quo, no qual inclusive as mais clamorosas desigualdades já estão 'estruturalmente' entrincheiradas e protegidas. Portanto, ela pode se permitir ser 'consensual', 'orgânica', 'participativa' e assim por diante, reivindicando também a manifesta justeza da 'moderação', 'objetividade' e 'neutralidade ideológica' (dominantes)” (MÉSZÁROS, 1994, p. 9). 
do marxismo, procuraram compreender as vias de objetivação do capitalismo no Brasil, introduzindo entre nós formulações teóricas consagradas desde Marx e Engels, e pautadas, sobretudo, nos casos clássico, democrático e prussiano, tardio, antidemocrático.

A discussão insere-se nos fundamentos de Lênin que, de uma maneira mais geral, considera que:

Uma exigência incondicional da teoria marxista na análise de qualquer questão social é a sua colocação dentro de um quadro histórico determinado e, depois, se se tratar de um só país (por exemplo, do programa nacional para dado país), a consideração das peculiaridades concretas que distinguem esse país dos outros nos limites de uma mesma época histórica (LENIN, 1976, p. 515) ${ }^{7}$.

De modo mais específico à problemática, é de Lênin ainda a distinção entre aquelas formas de transição para o capitalismo: os casos clássicos - ou via revolucionária - referem-se aos países que viveram experiências de ruptura radical e violenta com as formas de produção características do passado feudal; já o caso prussiano - ou via reformista - "corresponde ao caminho das dilatações, dos adiamentos, de agonia dolorosa e lenta", no qual o processo de industrialização é realizado mediante "reformas e não revolução".

Já se tem notícia deste debate no Brasil desde as décadas de 1920 e 1930. Na ocasião, algumas das mais inflamadas teses acerca dos problemas brasileiros e latino-americanos serviram de base para o programa da Internacional Comunista para a América Latina. De modo breve, essas teses tentam aproximar a história do continente das características que marcam o chamado caso clássico, e entre elas figura um passado feudal em vias de superação e em transição para

7 A mesma preocupação é conjugada por Lukács (1972): “Sem descobrir os fundamentos reais da situação histórico-social, não há análise científica possível. E isto que dizemos vale também, naturalmente, para as considerações que seguem. Não pretendemos com elas, de modo algum, oferecer um esboço de uma caracterização científica de certas filosofias ou correntes filosóficas. Só tratamos de por em relevo determinados aspectos, os mais gerais, como emanados da igualdade - geral - da economia imperialista; emanados, por suposto, nas distintas etapas de desenvolvimento dos diversos países, no processo de desenvolvimento desigual do imperialismo, o qual, sendo iguais os fundamentos, provoca ao mesmo tempo diferenças concretas” (p. 15). 
a democracia burguesa. No Brasil os expoentes dessa tendência foram Nelson Werneck Sodré e Alberto Passos Guimarães.

Certamente que, dada a magnitude tomada pela questão, algo que merece um estudo rigoroso e de longo prazo - não se pretende entrar aqui nos seus meandros, nem lhes julgar os acertos ou os equívocos. Por ora, gostaríamos de fazer menção à potencialidade revolucionária das análises derivadas da postura teórico-metodológica de realizar o movimento dialético concreto entre o universal, o particular e o singular. Com vistas a isso, Lukács propõe:

Que se pense na observação de Marx sobre a universalidade e a particularidade quando enfrenta o problema histórico da essência do capitalismo. Na particularidade, na determinação e na especificação, portanto, está contido um elemento de crítica, de determinação mais próxima e mais concreta de um fenômeno ou de uma lei. É uma concretização crítica, obtida graças à descoberta das reais mediações para cima e para baixo na relação dialética do universal e do particular. Apenas neste sentido deixam de surgir equívocos, ou seja, quando na particularidade enxergarmos, pelo menos em igual medida, tanto um princípio de movimento do conhecimento quanto uma etapa, um momento, do caminho dialético (1965, p. 108).

Na direção apontada, Carlos Nelson Coutinho, em seus estudos estéticos - sobretudo, na análise da obra de Lima Barreto em Realismo e anti-realismo na literatura brasileira -, introduz entre nós a categoria da particularidade histórica, apoiando-se nos essenciais estudos lukácsianos sobre a via prussiana. Fundamentais ainda às suas análises são as contribuições acerca da transição fundamentada no conceito de revolução passiva que irá buscar em Gramsci. ${ }^{8} \mathrm{~A}$ mesma linha de raciocínio é seguida por Luiz Werneck Vianna que traz contribuição decisiva à questão em seu livro Liberalismo e sindicato no Brasil.

De fato, há que se reconhecerem as muitas semelhanças que a experiência brasileira guarda com o processo alemão e mesmo

8 Para Gramsci, o conceito de revolução passiva possui “dois princípios básicos: 1) nenhuma formação social desaparece enquanto as forças produtivas que nela se desenvolveram encontrarem lugar para um ulterior movimento progressista; 2) a sociedade não assume compromissos para cuja solução ainda não tenham surgido as condições necessárias etc.” (GRAMSCI, 1978, p. 75). 
italiano. Mais importante do que estabelecer comparações entre os países, porém, é enfatizar que por intermédio desses referenciais de análise ficam abertos e mais iluminados os caminhos que conduzem às debilidades das nossas singularidades históricas, não só para conhecê-las, mas para superá-las. ${ }^{9}$

A via prussiana é também a base sobre a qual José Chasin enfrenta a problemática da nossa constituição histórica; no seu caso, para defender a tese de que o processo brasileiro encerra-se na particularidade da objetivação da via colonial para o capitalismo. E, para ele, diferentemente do processo alemão, o "verdadeiro capitalismo" no Brasil estaria predestinado, desde a colonização, a uma incompletude crônica, insuperável. Ou seja:

Em ambos os casos o desenvolvimento é lento e retardatário em relação aos casos clássicos. Mas, enquanto a industrialização alemã é das últimas décadas do século XIX, e atinge, no processo, a partir de certo momento, grande velocidade e expressão, a ponto da Alemanha alcançar a configuração imperialista, no Brasil, a industrialização principia a se realizar efetivamente muito mais tarde, já num momento avançado da época das guerras imperialistas, e sem nunca, com isto, romper sua condição de país subordinado aos pólos hegemônicos da economia internacional. De sorte que o "verdadeiro capitalismo" alemão é tardio, se bem que autônomo, ao passo que o brasileiro, além de hipertardio, é caudatário das economias centrais. (idem, p. 156)

Independentemente da matização interpretativa observada, a industrialização constitui aspecto essencial para algumas das mais significativas teorias marxistas da transição. É importante lembrar também que a elaboração de todas elas acontece sob as condições mais ou menos favoráveis da longa fase de ascensão histórica do capital, cuja plenitude foi sentida, sob a vigência do imperialismo, de modo bastante desigual. Durante esse período, o sistema de metabolismo social totalizante do capital avançava, desenvolvia-se e ainda podia protelar o agravamento das contradições - inevitavel-

9 Ricardo Antunes (1982), no seu livro Classe operária, sindicatos e partido no Brasil - da revolução de 30 até a Aliança Nacional Libertadora faz uma síntese bastante elucidativa da questão. 
mente criadas, insolventes e, portanto, acumuladas - utilizando-se justamente da sua estrutura hierárquica e desigual para transferir o pior dos seus efeitos do centro para a periferia. ${ }^{10}$

A despeito disso, um desenvolvimento industrial pleno era ainda visto não somente como possibilidade, mas, e acima de tudo, como necessidade histórica tendo em vista o sentido civilizatório do processo associado ao desenvolvimento das instituições democrático-burguesas. Entre elas, o Estado independente figurava como a conquista mais importante contra a superexploração à qual eram submetidos os trabalhadores dos países "subdesenvolvidos".

Em que pese toda a relevância da discussão a respeito das particularidades históricas que compõem as relações desiguais da ordem internacional do capital, discussão da qual o presente estudo considera-se devedor, o declínio dessas interpretações críticas (em muitos casos, abandono mesmo) coincide com o avanço da globalização. Velhos e novos adoradores do capitalismo, principalmente depois da queda do socialismo de tipo soviético, vêm se superando na arte de ressaltar as "positividades" do sistema, decretando até mesmo a obsolescência da luta de classes, das ideologias, do valor trabalho, das contradições, da emancipação pelo socialismo. Em poucas palavras, nesta cena marcada por tão profundo refluxo revolucionário, sobejam as prerrogativas mais decadentes e irracionalistas da ideologia burguesa.

István Mészáros intervém na questão para desmistificar o triunfalismo vigente com sua tese sobre a crise estrutural do capital, uma crise irreparável do sistema, cuja reprodução só pode realizar-se mediante mecanismos essencialmente destrutivos. Mészáros jamais negou o caráter crônico das crises que abalam o sistema, mas a atual, diferentemente das crises cíclicas, reformáveis e seguidas de longos períodos de crescimento econômico, graças ao desenvolvimento desigual e combinado, advém de uma situação em que:

10 "O efeito geral da exportação de capital é retardar o amadurecimento das contradições do processo de acumulação nos países exportadores e apressar seu aparecimento nos países importadores. Em suma, há a tendência de que a taxa de desenvolvimento do capitalismo nas várias partes da economia mundial seja nivelada pelos movimentos de capitais" (SWEEZY, 1976, p. 323). 
A devastação sistemática da natureza e a acumulação contínua do poder de destruição - para as quais se destina globalmente uma quantia superior a um trilhão de dólares por ano - indicam o lado material amedrontador da lógica absurda do desenvolvimento do capital. Ao mesmo tempo, ocorre a negação completa das necessidades elementares de incontáveis milhões de famintos: o lado esquecido e que sofre as consequiências dos trilhões desperdiçados. O lado humano paralisante deste desenvolvimento é visível não só na obscenidade do "subdesenvolvimento" forçado, mas em todos os lugares, inclusive na maioria dos países de capitalismo avançado. O sistema existente de dominação está em crise porque sua raison d'être e sua justificação histórica desapareceram, e já não podem mais ser reinventadas, por maior que seja a manipulação ou a pura repressão (MÉSZÁROS, 2002, p. 801).

\section{A periferia e os novos desafios da transição socialista}

Pois bem, neste quadro desolador, e por tudo o que se discutiu aqui, resta saber se para desobstruir os minados caminhos da transição existe ainda alguma necessidade histórica para a questão nacional tendo em vista as formas históricas particulares de objetivação do capitalismo.

Se pensarmos a questão do ponto de vista do capital, do mercado, do desenvolvimento da indústria capitalista, das instituições democrático-burguesas, enfim, dos aspectos que outrora cumpriram papel civilizatório, papel este tão amplamente cobiçado e perseguido pelas nacionalidades de extração colonial, diríamos que não. Hoje, em todas as partes do mundo, independentemente dos caminhos históricos tomados para se chegar ao estágio atual do capitalismo, o desenvolvimento dos meios de produção comandado pelo capital, perdeu a sua necessidade histórica. As formas correlatas de nacionalismo, alienadas pelas prerrogativas atuais da chamada globalização, só podem manifestar-se sob formas as mais grotescas, irracionalistas, fundamentalistas.

Se pensarmos a questão do ponto de vista do trabalho, das imediatidades e urgências advindas da precarização à qual é submetida a maior parte da classe trabalhadora, independentemente se a sua base nacional trilhou a via clássica, a via prussiana ou a via colonial, diríamos que absolutamente não. Isso porque qualquer que seja a forma 
de nacionalismo patriótico estimulado pela reserva de mercado - no caso, mercado de trabalho - precisa ser definitivamente superada pelos trabalhadores, sob pena de estarem sempre trocando a sua necessária consciência de classe pela consciência nacional chauvinista que esfacela a classe e convém única e exclusivamente ao capital.

Mas, é do ponto de vista do trabalho que também poderíamos afirmar sim a necessidade histórica da crítica imanente às particularidades nacionais. Sobre a questão, porém, é preciso enfrentar o desafio que hoje representa o fracasso da proposição original das vias de objetivação capitalista, de ir ao limite máximo do desenvolvimento nacionalmente independente do processo de industrialização para se atingir o amadurecimento necessário à transição socialista.

Isso quer dizer que o momento mais desenvolvido do sistema do capital é ainda mais desfavorável à transição do que antes. Hoje, a plenitude funcional das instituições democrático-burguesas equivale, no mesmo grau, ao empobrecimento da classe trabalhadora golpeada sucessivamente pelos sindicatos e partidos políticos, formas de organização nas quais, outrora, depositou-se expectativa revolucionária ${ }^{11}$. Da mesma forma que o desenvolvimento global do capitalismo não representou para os países de extração colonial a superação da sua condição periférica.

A via prussiano-colonial vem reproduzindo-se e atualizando a inserção periférica do Brasil e demais países da América Latina no sistema sócio-metabólico do capital. Essa vem se confirmando como a característica mais imanente à história burguesa do continente, característica que não foi nem jamais será superada por Estados nacionais mais ou menos democráticos, nem por políticas econômicas mais ou menos agressivas que ousem superar o historicamente velho.

As atuais condições de subordinação que o capital impõe sobre o trabalho, algo que implica na reprodução das desigualdades e dos mecanismos de dominação nacional e internacional, hoje,

11 Sobre a política, impressiona a atualidade das análises de Marx: "Quanto mais poderoso é o Estado e, portanto, quanto mais político é um país, tanto menos está disposto a procurar no princípio do Estado, portanto no atual ordenamento da sociedade, do qual o Estado é a expressão ativa, autoconsciente e oficial, o fundamento dos males sociais e a compreender-lhes o princípio geral” (MARX, 1995). 
mais ainda do que no passado recente, confirmam, para toda a classe trabalhadora, a necessidade ontológica da crítica imanente às análises mediadas pelas particularidades históricas e pela questão nacional. Enfatizamos, ainda, o sentido potencializado que essas questões adquirem para os trabalhadores que habitam o mundo das periferias, os mesmos que, há séculos, absorvem o permanente desequilíbrio criado pelas contradições do sistema, os pioneiros a provar das agruras da precarização. Arriscamos dizer por isso que a atualidade da crítica ontológica e algo instintiva da particularidade histórica objetivada na via prussiano-colonial vêm manifestando-se e evocando a necessidade de soluções definitivas nem só para as velhas e nem só para as novas, mas para todas as contradições que vêm desembocando nas nações que compõem a parte meridional das Américas.

Sob a ótica do trabalho, essa particularidade histórica, comum a todos os países latino-americanos, particularidade que um dia foi considerada a sua maior debilidade histórica, hoje pode ser o seu maior trunfo. Melhor, pode ser um importante e decisivo fator de mediação capaz de conduzir dialeticamente as lutas baseadas nas singularidades históricas pelos novos movimentos sociais nacionais ${ }^{12}$ no sentido de uma ampla solidariedade nacional, continental, mundial.

À guisa de conclusão, diríamos que a defesa do estatuto ontológico marxiano conduz à premissa de que hoje há tão somente duas maneiras possíveis de enfrentar a questão nacional, independentemente se o caráter contingente do Estado ao qual se reporta for democrático, autoritário, liberal, neoliberal, não importa: ou a questão nacional vem emoldurada numa perspectiva alienada e alienante, condicionando-se à eterna reprodução em tal molde, ou a questão nacional parte dessa mesma perspectiva não para reproduzi-la, mas para superá-la. Radicalmente!

Recebido em 23 de março de 2008 Aprovado em 10 de junho de 2008

12 Formas alternativas de organização social, como parece ser o caso do MST no Brasil, por exemplo, são presas de muitas armadilhas; no caso aludido, os apelos do capital podem se tornar irresistíveis no discurso inflamado dos ventríloquos do planalto sob a forma provinciana e miserável das chamadas políticas afirmativas. 


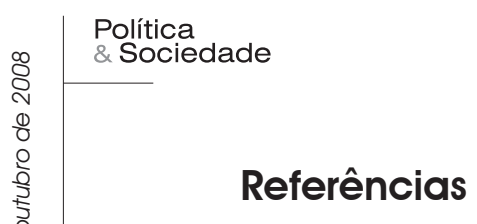

ANTUNES, R. Classe operária, sindicatos e partido no Brasil: da Revolução de 30 até a Aliança Nacional Libertadora. São Paulo: A. Associados/Cortez, 1982.

BARROS, R. A significação educativa do romantismo brasileiro: Gonçalves de Magalhães. São Paulo: Edusp/Grijalbo, 1973.

CHASIN, J. O integralismo de Plínio Salgado. São Paulo: C. Humanas, 1978.

COUTINHO, C. O significado de Lima Barreto na literatura brasileira. In.: Realismo e anti-realismo na literatura brasileira. Rio de Janeiro: Paz e Terra, 1972.

GRAMSCI, A. Maquiavel, a política e o Estado moderno. Rio de Janeiro: C. Brasileira, 1978.

LÊNIN, V. Sobre o direito das nações à autodeterminação. In.: Obras escogidas , Tomo IV. Moscú: Progreso, 1976.

LÖWY, M. Nacionalismos e internacionalismos. São Paulo: Xamã, 2000. LUKÁCS, G. Sobre la categoria de la particularidad. In.: Prolegómenos a uma estética marxista. México D.F.: Grijalbo, 1965.

. El asalto a la razón. La trayectoria del irracionalismo desde Schelling hasta Hitler. Barcelona/México D.F.: Grijalbo, 1972. MARX, K. Glosas críticas marginais ao artigo 0 rei da Prússia e a reforma social. de um prussiano. In. Revista Práxis, no 5, outubro/ dezembro de 1995, Belo Horizonte, 1995.

MÉSZÁROS, I. 1994. Filosofia, ideologia e ciência social. São Paulo: Ensaio.

. Para além do Capital. São Paulo: Boitempo, 2002.

. O poder da ideologia. São Paulo: Boitempo, 2004.

SODRÉ, N. Formação histórica do Brasil. São Paulo: Brasiliense, 1973.

SWEEZY, P. Teoria do desenvolvimento capitalista. Rio de Janeiro: Zahar, 1976.

VIANNA, L. Liberalismo e sindicato no Brasil. Rio de Janeiro: Paz e Terra, 1976. 